\title{
O trabalho dos professores de Biologia: a teorização a partir das contribuições dos pesquisadores da área de ensino de Ciências e Biologia
}

\section{The work of Biology teachers: theorizing from the contributions of researchers in Science and Biology education}

Rodrigo Diego de Souza

\begin{abstract}
Universidade de Brasília (UnB), Faculdade de Educação, Programa de Pós-Graduação em Educação em Ciências, Modalidade Profissional, Brasília, DF, Brasil.

Contato: professor.rodrigosouza@gmail.com
\end{abstract}

Resumo: Este artigo trata-se de um ensaio teórico-conceitual em que se apresenta uma teorização para o Trabalho dos Professores de Biologia. Constituem esta teorização as entrevistas realizadas com as pesquisadoras Krasilchik, Marandino, Selles, Cassiani, Valim, Galieta e o pesquisador El-Hani. Os relatos concedidos foram utilizados como referencial teórico, com o qual se teorizou que o Trabalho dos Professores de Biologia se fundamenta em quatro pilares que promovem maior compreensão nos âmbitos filosófico, pedagógico e político. Esses pilares são: (1) Concepções Filosóficas sobre a Educação e o Ensino de Biologia; (2) O Trabalho Pedagógico dos Professores de Biologia; (3) As Condições de Trabalho dos Professores de Biologia; e (4) Os Enfrentamentos, Lutas e Resistências dos Professores de Biologia.

Palavras-chave: Ensino de biologia; Condições do trabalho docente; Trabalho pedagógico; Entrevista; Pesquisador.

Abstract: This paper is a theoretical-conceptual essay and presents a theorization for the Work of Biology Teachers. This theory constitutes the interviews with researchers Krasilchik; Marandino; Selles; Cassiani; Valim; Galieta; El-Hani. The reports were used as a theoretical basis. With this foundation, it was theorized that the Work of Biology Teachers is based on four pillars. These four pillars promote greater understanding of the Work of the Biology Professor in the philosophical, pedagogical, and political spheres. These four pillars are: (1) Philosophical Conceptions about Biology Education and Teaching; (2) The Pedagogical Work of Biology Teachers; (3) The Work Conditions of Biology Teachers; (4) Confrontations, Struggles and Resistances of Biology Teachers.

Keywords: Biology teaching; Conditions of biology teachers; Pedagogical work; Interview; Researcher.

Recebido em: 28/12/2020

Aprovado em: 15/07/2021 


\section{Introdução}

Este artigo é um ensaio teórico-conceitual que apresenta uma teorização para o trabalho dos professores de Biologia. Para a construção dessa teorização, foram realizadas entrevistas com pesquisadoras e pesquisador reconhecidos nacionalmente e internacionalmente na área de Ensino de Ciências e Biologia, que também participam da consolidação desta área no contexto brasileiro. Foram entrevistadas as pesquisadoras Dra. Myriam Krasilchik, Dra. Martha Marandino, Dra. Sandra Lucia Escovedo Selles, Dra. Suzani Cassiani, Dra. Terezinha Valim Oliver Gonçalves, Dra. Tatiana Galieta e o pesquisador Dr. Charbel El-Hani ${ }^{1}$.

Este ensaio compõe uma pesquisa ampla de doutorado autorizada e aprovada pelo Comitê de Ética em Pesquisa com Seres Humanos da Universidade Federal de Santa Catarina (CEPSH-UFSC) ${ }^{2}$. De acordo com o Termo de Consentimento Livre e Esclarecido, os entrevistados foram nomeados pelo fato de serem pesquisadores reconhecidos e figuras públicas nas áreas de Educação e Ensino de Ciências e Biologia. Os relatos concedidos foram utilizados como referenciais para a teorização do Trabalho dos Professores de Biologia.

A problemática na qual se baseia a pesquisa de doutoramento concentra-se no Trabalho e na Formação dos Professores de Biologia, ancorando-se na fundamentação filosófica marxista de trabalho - que o compreende como fundamento ontológico do ser social, e, com base nele, a educação consiste numa das principais mediações e/ ou práxis sociais na formação humana (SOUZA, 2019). É na perspectiva de trabalho como totalidade social que se assenta, também, a prática pedagógica e o Trabalho dos Professores de Biologia (SOUZA, 2019). Em vista disso, originou-se a seguinte indagação: qual é o trabalho dos professores na Biologia?

Nesse pressuposto, com a revisão de literatura, constatou-se a ausência significativa de pesquisas sobre a temática (SOUZA, 2019), o que suscitou a importância de ouvir os pesquisadores da área sobre suas trajetórias de investigação e como significam o Trabalho dos Professores de Biologia. Assim, este ensaio apresenta o uso dos relatos dos entrevistados como referencial teórico que subsidia a teorização do Trabalho dos Professores de Biologia.

A teorização do Trabalho dos Professores de Biologia fundamenta-se em quatro pilares que emergiram de suas falas, os quais estão inscritos na dinâmica histórica de constituição da área e promovem maior compreensão desse trabalho no contexto brasileiro. Esses pilares são:

1. Concepções Filosóficas sobre a Educação e o Ensino de Biologia;

2. O Trabalho Pedagógico dos Professores de Biologia;

3. As Condições de Trabalho dos Professores de Biologia;

4. Os Enfrentamentos, Lutas e Resistências dos Professores de Biologia.

Apresenta-se, a seguir, a teorização de cada um desses pilares que constituem o Trabalho dos Professores de Biologia.

'Essas entrevistas foram cedidas ao autor nos anos de 2017 e 2018. Todas as transcrições desses pesquisadores com a indicação 'informação verbal' referem-se a essas entrevistas.

${ }^{2}$ Parecer $n^{\circ} 2.165 .105$. 


\section{O trabalho dos professores de biologia: concepções filosóficas sobre a educação e o ensino de biologia}

As concepções filosóficas da Educação, construídas historicamente pela humanidade, estão intrinsicamente na Educação e, por conseguinte, no Ensino de Biologia. Essas concepções dão subsídio para a própria prática pedagógica e para uma maior compreensão dos conteúdos biológicos, da apropriação desses conhecimentos pelos docentes e pelos alunos.

Então, todo meu trabalho de docência implica em entender a Biologia como uma ciência que tem que considerar uma explicação evolutiva, lado a lado, com a explicação do funcionamento do organismo em tempo presente. Então, todo meu olhar é sempre um olhar evolutivo e é pautado pela ideia de que a Biologia é uma ciência irredutível à Física e a Química. E, essa irredutibilidade é entendida com base na complexidade das interações transbiológicas. [...]. Então, essa concepção filosófica do que é a Biologia que foi o que inicialmente me levou a Filosofia da Biologia, que me tirou do laboratório de Biologia Molecular, me levou para a Filosofia da Biologia, foi um incômodo com a perspectiva analítica reducionista da Biologia. (EL-HANI, 2017, informação verbal).

A segunda face da concepção filosófica da educação e do ensino de Biologia no trabalho dos professores de Biologia corresponde, para El-Hani, à relação indissociável entre o Ensino de Biologia, a formação dos professores e as teorias educacionais. Essa relação engloba a discussão.

Compreende-se, assim, o trabalho dos professores de Biologia como particularidade - como mediação dos diferentes elementos que o compõem - entre a singularidade dos conhecimentos biológicos e o ensino desses conhecimentos, articulados com a Formação dos Professores e com as Teorias da Educação. Essas emergem da Filosofia da Educação e, por isso, consistem em concepções filosóficas da educação que estão subjacentes ao Ensino de Biologia.

Detalhadamente, El-Hani apresenta especificidades do Trabalho dos Professores de Biologia e, dessa relação indissociável entre o Ensino de Biologia, a Formação dos Professores e as Teorias Educacionais.

[...] se a gente pensar no que um professor precisa saber para exercer bem sua atividade profissional é uma enormidade de coisas. Ele precisa ter o domínio do conteúdo que vai ensinar. Eu costumo dizer que conteúdo de má qualidade bem ensinado é horrível. Você ter alguém que domina muito os conhecimentos pedagógicos, sabe muito bem conduzir processos de ensino e aprendizagem em sala de aula, mas, infelizmente ensina coisas equivocadas que são muito bem aprendidas e depois dá dificuldade para os alunos para o resto da vida. Então o domínio do conteúdo é importante. Não é suficiente nem de longe, mas ele é importante, é a primeira demanda de formação. Uma segunda demanda que é óbvia, tem que saber sobre Teorias Educacionais, sobre Metodologia de Ensino. Mas, saber transportar isso para a sala de aula. (EL-HANI, 2017, informação verbal).

[...] o professor precisa também ter uma formação básica de Filosofia da Educação, senão não consegue tomar decisões que sejam bem fundamentadas em sala de aula. Ele tem que saber aspectos da História e da Filosofia da área específica que ele ensina, se for de Biologia. História e Filosofia da Biologia, tem que saber um pouco de Psicologia, ter que lidar com os alunos, Administração, Relações Humanas. Realmente é um conjunto de exigências profissionais muito grandes. E uma capacidade de adaptação. Isso é uma característica fundamental do Trabalho Pedagógico. (EL-HANI, 2017, informação verbal).

Referente aos aspectos apresentados nas entrevistas por Charbel El-Hani, Martha Marandino também aponta relações entre os conhecimentos específicos das Ciências Biológicas e os conhecimentos pedagógicos na Formação dos Professores de Biologia. 
E eu acredito que tem outro desafio, que eu diria que é da própria formação [...] do campo conceitual e do conteúdo pedagógico, também ligado à formação do professor nas Ciências Biológicas, nos bacharelados e nas licenciaturas que, se por um lado, demandam exigências de conteúdos conceituais, uma formação nessa área, por outro lado, uma formação de conteúdos pedagógicos. (MARANDINO, 2017, informação verbal).

Relacionado aos aspectos apontados, Ayres (2005) salienta que a formação dos professores de Biologia ocorre num "território contestado", no qual as tensões entre o bacharelado e a licenciatura estão subjacentes.

Essas tensões não se colocam apenas por ocasião das relações entre os conhecimentos específicos e os conhecimentos pedagógicos, mas também nos aspectos políticos que balizam a organização curricular dos cursos de licenciatura em Ciências Biológicas e de outras licenciaturas.

Os aspectos políticos da organização curricular das licenciaturas estão, no contexto brasileiro, em sua gênese. Desde as primeiras experiências de formação de professores elaboradas na Universidade de São Paulo (USP), em 1934, por Fernando de Azevedo, e na Universidade do Distrito Federal (UDF), em 1935, por Anísio Teixeira, já se observava a origem do denominado modelo " $3+1$ " de formação. Posteriormente, o modelo foi consolidado e se tornado padrão para todas as universidades pelo Estatuto das Universidades Brasileiras, por meio da Faculdade Nacional de Filosofia (FNFi), da recém-criada Universidade do Brasil (UB), após a extinção da UDF (AYRES, 2005).

No modelo "3+1", a formação de professores se dava nos três primeiros anos do curso de formação básica dos bacharelados, para então, no último ano de curso, introduzir a formação pedagógico-profissional com a disciplina de Didática e a Prática de Ensino (atualmente os Estágios Supervisionados). (AYRES, 2005).

Mesmo com a Reforma Universitária de 1968, o modelo "3+1" manteve-se. Observando-se novas perspectivas e políticas para a formação de professores apenas nos anos 2001 e 2002, com as Diretrizes para a Formação de Professores (BRASIL, 2001, 2002a, 2002b). Dentre essas também se colocam elementos de análise crítica às quais não iremos adentrar nesse momento.

De todo modo, as concepções filosóficas sobre a Educação em Ciências e Biologia são indissociáveis do Trabalho Pedagógico dos Professores de Biologia, pois elas atribuem sentido e contribuem para que a Prática Pedagógica aconteça como práxis. Entretanto, elas também estão atreladas à formação dos professores, pois: qual formação? Para qual professor a ser formado? Em quais modelos de formação? O que implica também nas tensões que estão colocadas à organização curricular das licenciaturas, às políticas de formação de professores, às relações entre os bacharelados e as licenciaturas, entre os conhecimentos específicos e os conhecimentos pedagógicos.

Nessa direção, as discussões têm continuidade, balizando o Trabalho Pedagógico dos Professores de Biologia na prática pedagógica nas aulas de Ciências e Biologia.

\section{O trabalho pedagógico dos professores de biologia}

Dentre os diferentes aspectos que compõem o Trabalho Pedagógico dos Professores de Biologia, pontualmente, a pesquisadora cânone da área, Myriam Krasilchik contribui com aspectos importantes ao trazer elementos fundamentais para a prática docente no Trabalho Pedagógico dos Professores de Biologia: 
professores de Biologia para realizar plenamente o seu trabalho necessitam contar com um laboratório bem montado com equipamento adequado, auxílio técnico e tempo para preparação de atividades em classe e em ambiente natural. Essas condições ideais extremamente raras nas nossas escolas, mas é sempre necessário reivindicá-las sem prejuízo de realizar imprescindíveis atividades práticas mesmo nas condições mais precárias. Atualmente, a maioria das escolas não tem condições que permita trabalho experimental e projetos individuais ou realizados em grupo. No entanto, é essencial que o docente mesmo em condições difíceis organize aulas práticas para o aluno fazer observações, obter dados, análise e discuta o que observou e seu significado. Incluir no programa além das questões rotineiras tempo para trabalho de campo, visita a museus, entre outros. (KRASILCHIK, 2017, informação verbal).

\section{Krasilchik complementa:}

O Trabalho Pedagógico deve ter sempre o objetivo de dar liberdade aos estudantes para compreender o que estudam, não buscando apenas recompensa de notas como resultado de memorização de fatos e ideias apresentadas pelos livros ou pelo professor. [...]. O fundamental é manter um clima de liberdade onde todos possam expressar suas dúvidas e opiniões. (KRASILCHIK, 2017, informação verbal).

Krasilchik também salienta que "os objetivos maiores da docência, além de prover os alunos com princípios, e ideias, e informações de Biologia é formar cidadãos preparados para tomar decisões que afetam a qualidade de vida individual, social e da comunidade em geral".

Subjacentes aos aspectos e às ações didáticas que compõem a prática docente e Pedagógica, na perspectiva da totalidade, estão as mediações entre os complexos sociais, culturais, ideológicos, entre outros, que também permeiam e determinam o Trabalho Pedagógico dos Professores de Biologia. Cassiani ilustra esses aspectos, quando diz:

Então o sentido de trabalho para mim é uma coisa que envolve muitas questões éticas, políticas, de transformação social. [...]. Acredito que está muito voltado para um mundo melhor, menos desigual, que as injustiças sejam menores, que a gente consiga chegar num mundo sem racismo, homofobia, machismo... tentar pelo menos melhorar isso, porque estamos vivendo uma situação oposta aqui na nossa sociedade. Então a luta continua, mas considero que é isso, o sentido do trabalho é para isso, uma educação para paz, uma educação que a gente consiga mediar esses conflitos, que a gente seja solidário, construa coletivamente a autonomia. (CASSIANI, 2018, informação verbal).

Relativo a isso, Cassiani explicita as relações entre os aspectos supracitados e a Formação dos Professores de Biologia, de modo especial, no Estágio Curricular Supervisionado. Neste também se revelam as relações estabelecidas entre o Trabalho, a Escola e a Universidade nos processos formativos dos professores de Biologia, quando diz:

Considero que a disciplina de Estágio Curricular Supervisionado Obrigatório acaba fazendo com que a gente fique com esse contato com a escola. Gosto muito de trabalhar com Estágio na Formação Inicial, pensando nessas questões que envolvem o Ensino de Ciências, de uma forma ampla, envolvidas às questões econômicas, políticas, sociais que estão aí, que fazem parte do currículo de ciências e, que muitas vezes, os nossos alunos não percebem. Muitos de nossos futuros professores, não percebem a importância de pensar um currículo que envolva essas questões. Penso que isso é um desafio, não é? Já que você está pensando na questão do trabalho dos professores de biologia, gostaria de ressaltar que essas ações que envolvem um currículo mais crítico, está presente na fala deles, porque eles ouvem isso durante a licenciatura, está nos documentos, até na Base [Base Nacional Comum Curricular] tem essa questão da formação cidadã etc. Então pondero que esse acompanhamento dentro da licenciatura, dentro do Estágio é super importante trabalhar essas questões do que significa um pensamento crítico, o que é ser crítico, o que é um currículo que envolve essas questões. (CASSIANI, 2018, informação verbal). 
O Estágio Supervisionado no Ensino de Ciências, atividade obrigatória dos cursos de Licenciatura em Ciências Biológicas, em consonância com os documentos oficiais que o regulamentam (BRASIL, 1996, 2001, 2002a, 2002b, 2015a, 2015b), representa um relevante espaço/tempo no processo formativo dos professores em formação inicial.

Ressalta-se que as diretrizes vigentes para a Formação de Professores no Brasil durante a pesquisa eram o Parecer CNE/CP n 2 (BRASIL, 2015a) e a Resolução CNE n 2 (BRASIL, 2015b); porém, apontam-se as Diretrizes de 2002 (BRASIL, 2002a, 2002b), pois são anteriores às vigentes na ocasião. Em 2019 e de 2020 foram publicadas as Diretrizes e Bases Nacionais para a Formação Inicial e Continuada de Professores, as quais alinham a formação docente à Base Nacional Comum Curricular (BRASIL, 2019, 2020).

Com relação aos Estágios na Formação dos Professores de Biologia, na relação entre Escola e Universidade, os quais se constituem também no Trabalho Pedagógico dos Professores de Biologia, em serviço e em formação inicial, Suzani Cassiani também salienta, a partir das vivências e práticas construídas no seu contexto, o seguinte:

\begin{abstract}
Apesar de todo esse desmonte da escola, e eu passei por isso também nas escolas enquanto estudante dos anos 1970 e professora da escola básica nos anos de 1980 e 1990, tem muita gente boa nas escolas e tem muitas escolas boas. Por exemplo, os professores de ciências e biologia daqui de Florianópolis, onde fazemos os estágios. Eu fico muito encantada porque encontro a cada dia, pessoas muito comprometidas e responsáveis com a educação. Claro que a gente necessita construir parcerias com os professores do estágio, pois a escola é co-formadora de professores. Então, tem uma coisa básica nesse processo de receber os estagiários e para os professores os receberem, é que eles gostem dessa ação e não sejam obrigados a recebê-los. Eu já faço essa construção de parcerias há muitos anos, nós conseguimos fazer uma parceria ness a construção de conhecimentos sem fazer uma atividade de cima para baixo, uma atividade na qual a escola e o professor também são coformadores de professores. O professor é muito importante dentro do estágio porque ele forma também os professores, não somente a universidade. Eu fico muito encantada com o que eu vejo nas escolas, é incrível. (CASSIANI, 2018, informação verbal).
\end{abstract}

Nessa direção, os estágios consistem num espaço/tempo que é propício para a construção profissional da identidade dos docentes em formação no cotidiano da escola, espaço privilegiado de formação (CANDAU, 2003; PIMENTA; LIMA, 2004) por meio dos conhecimentos produzidos na e a partir da docência.

Ressalta-se a importância do Estágio Supervisionado como momento de síntese, das articulações que integram os conhecimentos biológicos e os conhecimentos pedagógicos, na perspectiva da totalidade da prática pedagógica como ponto de partida e ponto de chegada, o que possibilita a construção da práxis educativa, como também assinala Marcelo García (1999, p. 29): “[...] de modo a que aprender a ensinar seja realizado através de um processo em que o conhecimento prático e o conhecimento teórico possam integrar-se num currículo orientado para a ação".

As relações estabelecidas entre a Escola e a Universidade noTrabalho Pedagógico dos Professores de Biologia também ocorrem em outros espaços/tempo, não apenas nos Estágios. Nesse sentido, Tatiana Galieta indica outros modos em que se observam essas relações, sendo um deles por meio do Programa Institucional de Bolsas de Iniciação à Docência (PIBID):

O que eu percebo, eu não sou professora de estágio, então estou na escola com o PIBID, e o PIBID, ele é um programa fantástico. [...]. É bacana porque a gente tem uma página no Facebook que a gente vai postando as fotos das atividades e é muito legal porque todo mundo fica sabendo, o que todo mundo está fazendo, em todas as escolas. E a gente vê que teve um início, pensando 
especificamente no Ensino de Biologia, que ele era muito experimental, era muito aquela coisa de prática para prática para comprovar teoria. E a gente já percebe um movimento mais reflexivo sobre a função do Ensino de Ciências e Biologia. E percebo que tem um pouco disso, da gente falar que o professor tem que ser professor pesquisador. Mas, como nessas condições objetivas de trabalho que esse professor vem enfrentando, como eles vão ser reflexivos, como vão ser pesquisadores da sua prática? (GALIETA, 2017, informação verbal).

O PIBID consiste num programa que oferece bolsas de iniciação à docência aos licenciandos e aos professores que os recebem nas escolas e fazem a supervisão e o acompanhamento dos alunos. O programa é coordenado por professores da universidade que orientam e acompanham os graduandos, articulando-se assim a Escola e a Universidade na Formação dos Professores, os dois lócus de formação. Dessa forma, o PIBID estabelece articulações entre a educação superior por meio das licenciaturas, da escola e da formação dos professores no cotidiano; isto é, na realidade de trabalho pedagógico no qual se inserem.

Nesse contexto, o PIBID também possibilita a organização do Trabalho Pedagógico dos Professores de Biologia na perspectiva do Trabalho Coletivo, no planejamento e na prática docente a partir da coletividade. O trabalho coletivo contribui para a construção de práticas pedagógicas que superem a concepção do trabalho pedagógico como algo isolado ou fragmentado. Essa concepção - que muitas vezes reforça a cultura do individualismo tão presente na sociabilidade capitalista faz emergir, a partir do individualismo, as disputas e a competitividade; dessa forma, coloca em xeque o trabalho dos professores, ao mesmo tempo que os responsabiliza e culpabiliza pelos insucessos e fracassos em sala de aula (ALONSO, 2002).

Por outro lado, o trabalho coletivo é pautado numa perspectiva democrática de educação, a partir da ação conjunta dos professores para alcançar um objetivo comum traçado na coletividade. Desse modo, desde o planejamento com a discussão de ideias, propostas de aulas, possibilidades didáticas, consensos e dissensos, tomadas de decisão à prática pedagógica, o trabalho é entendido na perspectiva da totalidade em vista dos objetivos comuns e coletivos (ALONSO, 2002).

O PIBID pode contribuir na formação inicial dos professores de Ciências e Biologia não apenas na articulação entre a Universidade e a Escola, mas também nas contribuições do trabalho coletivo como possibilidade para a organização do Trabalho Pedagógico dos Professores de Biologia, também como espaço/tempo de formação.

Para além dos aspectos didático-pedagógicos que compõem o Trabalho Pedagógico dos Professores de Biologia, Galieta salienta a seguinte constatação sobre a bolsa do PIBID que os professores supervisores e orientadores recebem: "[...] não é um detalhe essas professoras terem bolsa, é vital. E, muitos de nós, e eu me incluo nisso, fizemos da bolsa do PIBID o salário, é o que entra e a gente paga conta. Não é um a mais. Então essa remuneração do PIBID é vital para isso" (GALIETA, 2017, informação verbal).

Galieta relata isso porque a Bolsa do PIBID - que poderia ser apenas um prólabore como pagamento para o trabalho realizado de acompanhamento, orientação e supervisão dos licenciados do PIBID - tornou-se, para ela e as demais professoras, o salário; a fonte de renda principal na crise que afetou o estado do Rio de Janeiro, no Brasil, de modo mais intenso entre os anos de 2016 e 2018. Isso comprova o cenário drástico e as condições precárias de trabalho que acometem os docentes e as implicações disso no Trabalho Pedagógico dos Professores de Ciências e Biologia, e das demais áreas curriculares. O que torna mais latente a indagação retórica de Galieta: 
"Como nessas condições objetivas de trabalho que esse professor vem enfrentando que acabei de falar, como eles vão ser reflexivos, como vão ser pesquisadores da sua prática?" (GALIETA, 2017, informação verbal).

Consoante às contribuições demonstradas por Cassiani - sobre as Relações entre o Trabalho Pedagógico dos Professores de Biologia e o Estágio Curricular Obrigatório - e as indagações e problemáticas levantadas por Galieta - a respeito do PIBID, o Trabalho Coletivo e as condições precarizadas de trabalho para a sobrevivência - a pesquisadora Sandra Selles também sinaliza as implicações das condições materiais e sociais no Trabalho dos Professores de Biologia.

Selles aponta como as condições de trabalho afetam diretamente o planejamento dos professores. Ela também contribui com uma definição de Trabalho Pedagógico do Professor de Biologia, definindo-o de modo múltiplo, ao afirmar:

\begin{abstract}
Essas condições de trabalho [precarização, intensificação, baixos salários etc.] influem como ele [professor] vai planejar, como ele vai ler, dedicar suas horas para seu trabalho. E, naturalmente, como ele vai buscar para além dessa ação diária, dessa dimensão de agir na escola, como ele vai encontrar tempo para pensar sobre isso, para refletir, para pesquisar, para entender um pouco mais seu objeto de ensino, aquilo que ele vai ensinar. Então, eu considero, que primeiramente, se eu pudesse resumir, eu diria que o trabalho pedagógico é múltiplo, de modo geral ele tem muito pouco tempo para essa dedicação do seu dia a dia, do cotidiano do seu próprio trabalho e quem dirá para pesquisa, Ensino de Biologia. (SELLES, 2018, informação verbal).
\end{abstract}

Selles expressa a relação entre as Condições de Trabalho, as Resistências e o Trabalho Pedagógico dos Professores de Biologia, que também estão presentes nos relatos das pesquisadoras Cassiani, Galieta, Marandino e Valim. A seguir, delineiam-se, a partir das contribuições das pesquisadoras, reflexões sobre as Condições de Trabalho e o Trabalho dos Professores de Biologia.

\title{
As condições de trabalho dos professores de biologia e o trabalho pedagógico dos professores de biologia
}

As Condições de Trabalho impactam diretamente no Trabalho Pedagógico dos Professores. Os relatos das pesquisadoras Cassiani, Galieta, Marandino, Selles e Valim trazem essa questão, apresentando as lutas dos professores em diferentes estados e cidades brasileiras, que reverberam nos contextos onde as pesquisadoras atuam.

Marandino apresenta os aspectos que estão ligados às Condições de Trabalho dos Professores de Biologia e sua relação com a permanência dos estudantes nos cursos de Licenciatura, em especial, em Ciências Biológicas.

\footnotetext{
Vivemos em um momento caótico, muito difícil com relação a isso [condições de trabalho] e eu percebo uma mudança muito grande do momento em que eu fiz a opção pela minha carreira e esse momento atual, por mais que as perspectivas em Biologia não fossem promissoras em termos de salário e tudo mais, a questão do valor do profissional da educação só piorou, já não era grande, só piorou. [...]. Por outro lado, na universidade a gente tem a condição de ter contato com os alunos para além das disciplinas, via os projetos de bolsa da universidade e aí, nesse contato, eu fico mais próxima de saber dessas condições, você vê realmente as pessoas que precisam dessa bolsa para poder estar cursando a universidade, e você vê também que essas condições são muito difíceis mesmo, considero que tem um idealismo muito forte, tem uma contradição aí, por um lado, uma realidade que aponta para uma desvalorização total seja ela moral, ou seja, ela financeira, mas, por outro lado, vejo nos alunos que querem seguir carreira de professor, um ideal de mudança, de transformação, isso ainda está presente. (MARANDINO, 2017, informação verbal).
} 
Referente a isso, Valim, ao revisitar sua história e o trabalho como professora, também aponta a relação entre a formação pedagógica, o trabalho pedagógico e as condições de trabalho ao compartilhar um pouco de sua história:

[...] outro destaque foi com relação ao Ensino de Biologia e Ciências. Daí eu atribuo a um professor da Prática de Ensino. A Prática de Ensino era no último semestre, [que] fiz no $4^{\circ}$ ano a Prática de Ensino. [...]. A gente saia daquelas aulas, eu já estava lecionando, eu estava já na Escola Pública. Eu me lembro de que ele falou muito nos livros do Oswaldo Frota Pessoa. Eu penso que pode ter sido o primeiro livro que existiu no país, Como Ensinar Ciências. Eu cheguei numa livraria que tinha no caminho da escola e perguntei e me mostraram um amarradinho de dois [livros] que eram Biologia na Escola Secundária do Frota também, e Como Ensinar Ciências. Eu não tinha dinheiro nessa época, eu estava começando a lecionar e não tinha recebido salário, então eu vivia com os trocadinhos, mas os comprei.

[...] Eu tinha feito magistério. Eu já lecionava como contratada por causa da Biologia. Esse professor foi responsável por mexer com a minha cabeça para o Ensino de Ciências. Eu já tinha feito alguns cursos no (CECIRS), também no Centro de Ciências do Rio Grande do Sul. Mas, ali, eu senti o grande incômodo com tudo que eu tinha aprendido antes. Porque ele pedia, por exemplo, para a gente fazer o Plano de Aula para a turma que a gente iria assumir no Colégio de Aplicação. Eu parecia nunca ter ouvido falar em Plano de Aula e eu tinha feito duas didáticas. Então, ele mexeu com coisas que estavam adormecidas por um ensino bancário, para um ensino que a gente fazia até, por conta do meu ritmo, que era dividido entre o trabalho para a sobrevivência e o estudo na universidade. Mas, eu atribuo a ele esse desabrochar para enxergar as coisas de outro modo. (VALIM, 2017, informação verbal).

A pesquisadora Valim, ao apresentar um pouco das suas vivências, mostra como essa historicidade a transformou e a formou enquanto professora e pesquisadora no seu processo formativo, evidenciando-se o lugar do professor da disciplina pedagógica, especificamente de Prática de Ensino do curso de Licenciatura em Ciências Biológicas, como um exemplo da docência; por outro lado, o relato também mostra as dificuldades associadas às condições de trabalho.

Nessa história de vida e seu início como trabalhadora da educação na escola pública, enfatizam-se as con dições de salário e carreira semelhantes às contemporâneas. A dívida histórica brasileira com a docência e com a profissão docente corrobora a desvalorização profissional e as precárias condições de trabalho que implicam nas práticas docentes e na insatisfação dos professores na profissão.

Selles também ilustra essas condições a partir do contexto do estado do Rio de Janeiro:

Eu caracterizo essas relações [relações de trabalho] como relações bastante desfavoráveis aos professores de Biologia. E, eu considero que as condições de trabalho, de um modo geral, nas escolas públicas, nas escolas estaduais, nas escolas municipais. Mas, claro que estou falando de um lugar, de um Estado do Rio de Janeiro, onde as condições de trabalho nas escolas estaduais são bastante preocupantes, requer muito do professor. E me refiro também às questões que vão junto, da remuneração que está sempre aquém. Uma carreira que é difícil você desvincular dessas outras, desses outros elementos, das condições de trabalho, de remuneração, da valorização, do salário por conta de um atraso histórico, de uma dívida histórica que nosso país tem com a docência, com o sentido de docência. E coloca nosso professor de biologia nesse lugar de subalternidade, esse lugar muitas vezes de não se orgulharem daquilo que fazem. Então eu penso que todo professor de biologia como de que outra matéria, todo professor vivendo, tomando a profissão como um projeto de vida, tinha que estar muito mais feliz que infeliz, tinha que estar muito mais... Indo para o trabalho com muito mais prazer. (SELLES, 2018, informação verbal).

Galieta também apresenta as condições de trabalho dos professores de Biologia no contexto do Rio de Janeiro, especialmente as que dizem respeito aos Professores Formadores de docentes; e não apenas a estes, mas também a todos os professores 
universitários que são proletarizados, com jornadas de trabalho intensificadas e precarizadas. Desse modo, notabiliza-se a problemática vivida pelos professores da Universidade do Estado do Rio de Janeiro (UERJ), numa das maiores crises vividas na instituição nos anos de 2016 a 2018.

\begin{abstract}
Vou tentar pensar quando reconheci que a minha profissão docente era profissional. Porque eu acredito que tem uma dificuldade de reconhecimento principalmente do professor universitário como trabalhador. Isso eu tenho percebido principalmente na minha vivência nas assembleias docentes do nosso sindicato, a ASDUERJ [Associação de Docentes da Universidade do Estado do Rio de Janeiro], ao ANDES-SN [Sindicato Nacional dos Docentes das Instituições de Ensino Superior]. Os professores universitários têm uma tendência de não se reconhecerem como trabalhadores porque se consideram intelectuais, então é algo que vim constituindo ao longo do tempo. Então eu acredito que logo que me formei na graduação e fui trabalhar como professora em educação básica numa escola particular, eu pensava aquilo ali mais como um ganha pão do que necessariamente como um trabalho. E com o tempo só fiquei uns 3, 4 anos como professora de educação básica, fui percebendo que o meu trabalho não era só de formação dos meus alunos, meus estudantes, mas também era meu, de autoformação. $E$ foi quando senti uma necessidade de continuar estudando. Daí fui fazer mestrado, doutorado. E logo depois já virei professora universitária. Então fui professora na UFRJ como substituta, depois efetiva na Federal de Itajubá e há cinco anos na UERJ. Então percebo que a minha constituição como professora eu acredito que passa muito desse meu reconhecimento como trabalhadora e uma trabalhadora como qualquer outro trabalhador. Um trabalhador assalariado que vende sua força de trabalho, que seu espaço/tempo é organizado em função dessa relação com uma instituição. Então eu não consigo desvincular o meu trabalho, por exemplo, da instituição em que estou inserida. Reconheço meu trabalho mais ou menos como, não só, como também formo professores porque sou professora de licenciatura. Então não só nessa formação dos licenciandos, mas também numa formação minha como sujeito, como cidadã. E pensando dentro da minha participação na sociedade, isso passa obrigatoriamente pelas minhas relações de trabalho internas na minha instituição e externas com o governo, com os deputados que estão na ALERJ, segurando nosso plano de carreira. Então, tudo isso eu considero que acaba me constituindo enquanto trabalhadora e também me faz refletir o tempo inteiro sobre meu trabalho. (GALIETA, 2017, informação verbal).
\end{abstract}

Essa pesquisadora apresenta, articulada à trajetória acadêmica e profissional, a sua constituição como professora formadora de professores e a relação de tudo isso com o trabalho, de modo que se destaca as diferentes faces e contradições do trabalho na sociedade capitalista e a importância da consciência de classe, da conscientização enquanto classe trabalhadora. É apenas a partir da consciência de classe, do entendimento de que compõe a classe trabalhadora, que se torna possível a luta coletiva de todos os trabalhadores frente à degradação do trabalho socialmente humano, à degradação da vida.

Nessa direção, Galieta continua suas reflexões:

[...] essa tática de retirada de direitos trabalhistas é muito perversa. O arrocho que a gente vive na UERJ em todas as instituições de Educação e Ciência e Tecnologia do Rio de Janeiro é para isso, é para mostrar que o que você fizer aí está bom, a gente te dá três mil reais e você funciona uma universidade. No ano passado [2016] a gente recebeu cota de três mil reais, custeio de três mil reais/ mês. É uma unidade. Não tem como você fazer isso. As unidades que são as mais afetadas são as de Formação de Professores. São três unidades de Formação de Professores que são exclusivas. A minha que é a Faculdade de Formação de Professores, a Faculdade de Educação da Baixada Fluminense e tem o Cap/UERJ, o Colégio Aplicação, que forma professores também. Não é só uma unidade de educação básica, forma professores. São as três mais atingidas nessa crise toda. Por que como você traz dinheiro, investimento para a educação? Não é como uma engenharia que você faz um projeto com alguém que vai injetar grana aí? O primeiro nível a ser sucateado é o da Educação e o da Formação de Professores. É isso que a gente tem vivido lá. (GALIETA, 2017, informação verbal). 
De outro lado, frente às condições precárias e fragilizadas de trabalho, há resistências, há lutas e enfrentamentos dos docentes por condições dignas de trabalho e, por consequência, por uma Educação Pública e de Qualidade. Essas lutas, resistências e enfrentamentos são delineados pelas pesquisadoras nos diferentes contextos nos quais atuam.

\section{Os enfrentamentos, lutas e resistências dos professores de biologia}

Os relatos das pesquisadoras Cassiani, Galieta e Selles em suas entrevistas contribuem para delinear os enfrentamentos, as lutas e as resistências dos Professores de Biologia nos diferentes contextos em que atuam.

Cassiani traz as suas contribuições quando apresenta as relações entre a sua trajetória de vida e a formação na área de Educação em Ciências e Biologia, com suas experiências, vivências e trabalho como professora, traçando a historicidade que marca a sua formação.

Minha família é de operários, avó, avô, imigrantes italianos que trabalharam na roça. Então, o trabalho sempre foi uma coisa muito importante para a minha família. Muitas vezes até uma coisa subserviente, aos patrões... a gente foi criada nesse meio, pensando nessas questões do trabalho como algo muito importante e não algo que enobrece o patrão. Por outro lado, uma coisa de muita responsabilidade. Eu trabalhei quando adolescente [inicialmente aos 15 anos] em vários lugares, trabalhei em fábrica, numa loja que a gente era hiperexplorado [54 horas semanais]. Nessa época, eu comecei a estudar no ensino médio noturno. Depois aos 17 anos, quando entrei para a faculdade, eu tinha que viajar todo dia para Campinas de ônibus fretado. Nessa loja, o ônibus e as pessoas tinham que me esperar, porque os patrões não me liberavam nem cinco minutos para estudar. Era época da ditadura, um sentimento muito no começo de respeito com os patrões e, depois, um sentimento de revolta, quando eu passo a estudar essas coisas, passo a perceber que existe uma ditadura, 1979. Aí é que eu percebo que posso fazer outras coisas além de ser tão boazinha como eu era.

[...] Aí, quando eu começo a dar aula em 83 - me formei em 82 -, toda essa revolta, essa indignação com o trabalho, no qual eu era muito subserviente, ele vira outra coisa que é uma resistência a esse status que a gente tinha na época e uma possibilidade de também trabalhar com questões políticas dentro da escola. Isso transformou muito a minha vida, sempre com muita responsabilidade $e$ sempre com muito empenho e muita vontade de fazer a transformação, mas com todo esse pano de fundo político [...]. Quando eu vou fazer a especialização, eu escolho um grupo que vai pensar em questões políticas, sociais, econômicas, foi em 1988 essa especialização na Unicamp. Ela foi um divisor de águas para mim, foi muito interessante, muito importante, pois eu nem sabia que tinha pesquisa em educação. Então, todo esse meu empenho na escola e no trabalho que eu fazia em ensinar ciências, de pensar questões políticas, sociais por conta própria, sem ler nada dessas coisas, porque na minha faculdade eu não vi isso, tinha censura. Eu então começo a perceber que 'tem vida em outro planeta'. (CASSIANI, 2018, informação verbal).

Galieta, partindo da discussão sobre o desmonte da Universidade Pública, reflete e problematiza a própria realidade vivida na UERJ. A pesquisadora elabora articulações crítico-reflexivas que nos permitem entender o Trabalho Pedagógico como resistência na formação dos licenciados, nas atividades desenvolvidas nas escolas, no Pibid, nas relações da universidade com a comunidade.

Essas resistências e enfrentamentos, que são sintetizados nas lutas pela formação dos professores, pela universidade, pela escola, pela educação pública têm os sentidos e significados atribuídos à própria formação e aos próprios conteúdos ensinados e problematizados que compõem a formação: 
Então penso, qual o sentido do meu trabalho para esses futuros trabalhadores que virão a se tornar professores como eu e, que, dependerão também dos seus salários para viver. Então começo a pensar, será que minha função é só formar academicamente esses licenciandos e futuros professores? Será que minha função também não é formar para eles pensarem essas relações que falei antes, as relações institucionais, relações que não são institucionais e que perpassam o trabalho docente. Então estou vivendo um conflito com isso porque a gente quando passa a pensar assim, não recebo meu salário, mas estou vindo trabalhar, que exemplo estou dando para esses futuros trabalhadores quando estou dando um recado para eles, de que meu trabalho de repente não é importante ser remunerado. Então isso é algo que a gente vem conversando muito com os alunos e entre nós mesmos professores porque eu penso que é uma reflexão importante da gente fazer. Eu pelo menos tenho passado por isso, por um momento bastante delicado na minha constituição como professora trabalhadora, de perceber qual verdadeiro sentido da minha função quando estou em sala de aula. Porque a gente se reconhece como professor que ensina algo, ensina um conteúdo. Mesmo nós que somos professores de disciplinas pedagógicas, a gente tem conteúdo para ensinar. Eu como professora de Metodologia de Ensino, como professora de Ciência, Tecnologia e Sociedade, eu tenho conteúdos a serem ensinados. Mas, até que ponto esses conteúdos nesse momento são secundários? (GALIETA, 2017, informação verbal).

Considerar o Trabalho Pedagógico dos Professores de Biologia como resistência aos ataques à educação pública, de modo geral, consiste nessa constante indagação a respeito da 'função' dos nossos conteúdos na produção e na reprodução da vida no capitalismo. Além disso, reflete-se como nossos conteúdos podem possibilitar uma educação crítica, não na concepção de crítica presente nos documentos e políticas educacionais pautados na ideologia neoliberal.

A concepção de crítica da sociedade capitalista reverbera a ressignificação das teorias, posto que tudo é válido, tudo é aceito, tudo é considerado crítico, ainda que a 'cidadania crítica' presente em documentos como a Base Nacional Comum Curricular (BNCC) (BRASIL, 2018), reafirme uma educação crítica para uma semiformação, ou seja, para o não acesso dos alunos às perspectivas mais amplas de conhecimento, alinhadas aos valores da empregabilidade, da formação de mão de obra barata e de uma educação neotecnicista. As ressignificações das teorias também estão presentes nas pesquisas em educação, conforme afirma Moraes (2009b, p. 587-588):

Meu argumento é o de que, neste momento crucial para a compreensão das questões sociais, em que o capitalismo produz forte degradação da vida humana, verifica-se certa tendência de supressão do aprofundamento teórico nas pesquisas na área da educação, com gravíssimas implicações políticas, éticas, além, naturalmente, das epistemológicas. Esta tendência tem dupla vertente: em uma delas verifica-se a crescente influência do realismo empírico (Bhaskar, 1997, 1979, 1986 e 1993), movimento que prioriza a eficiência e a construção de um terreno consensual que reduz o horizonte da pesquisa e da formação docente ao saber tácito, à prática instrumental, plasmando-se o processo cognitivo no interior de limites que se definem pela formatação da capacidade adaptativa dos indivíduos e pela narrativa descritiva da experiência (Moraes, 2001, 2003). [...] Na outra, observa-se um aspecto ainda mais grave, o embaralhamento entre ceticismo epistemológico e relativismo ontológico, de acentuado perfil pós-moderno. Nossos conhecimentos são relativos, dizem, porque são sociais, históricos, contextualizados, conjunturais, culturais etc., e desse caráter transitório e relativo infere-se que nosso conhecimento não pode ser objetivo, será sempre um ponto de vista individual, de um grupo, de uma cultura. Ou seja, por atestar que ideias, teorias etc. opostas não podem ser objetivamente comparadas, conclui-se a impossibilidade da crítica, de cotejar as várias correntes de pensamento, pois mesmo reconhecendo o real, concluise que não se pode ter um conhecimento objetivo a seu respeito. 
Nessa direção, enfatiza-se neste ensaio uma teorização do Trabalho dos Professores de Biologia assentada numa concepção de Educação em Ciências e Biologia crítica-crítica, que viabilize os fundamentos para a crítica, uma apropriação dos conteúdos de Ciências e Biologia que amplie as visões de mundo dos alunos, com vistas à emancipação política e humana para a transformação da realidade, pois

A "teoria tem consequências". A opção está posta, escolhermos uma teoria
que contribua para perenizar o presente e administrar o existente, como as
várias versões da epistemologia da prática, particularmente na educação, ou
uma teoria que proceda à análise crítica do existente, que informe a prática
científica consciente de si mesma, pois é o processo histórico-crítico do
conhecimento científico que nos ensina (como seres sociais) a capacidade
emancipatória, que nos torna conscientes de nosso papel de educadores
que não ignoram que a transmissão do conhecimento e da verdade dos
acontecimentos é um instrumento de luta e tem a função de ser mediação na
apreensão e generalização de conhecimentos sobre a realidade objetiva, sob
a perspectiva de domínio sobre a realidade segundo as exigências humanas.
(MORAES, 2009a, p. 340).

Partindo das questões que se colocam ao trabalho dos professores de Biologia, das Condições de Trabalho e da possibilidade de uma Educação em Ciências e Biologia, para além das ressignificações da teoria, comprometida com uma criticidade crítica, Selles faz referência aos professores que - mesmo diante de tantas contradições, desafios, precarizações - lutam contra a maré, pois fazem resistência na cotidianidade em que produzem e reproduzem a sua vida:

[...] há professores que remam contra a maré, que conseguem a duras penas estabelecer relações com seus alunos e que realmente marcam as vidas desses seus alunos de um modo bastante impactante. Eu procuro isso em todos os professores, sem procurar nenhum professor modelo, sem procurar nenhum professor que a gente vá dar um prêmio, mas esse professor do dia a dia, esse professor comum, mas estar atento a como ele se significa, como ele dá sentido a sua própria vida no seu trabalho junto aos seus alunos. (SELLES, 2018, informação verbal).

Fundamentado nos relatos das pesquisadoras Cassiani (2018), Galieta (2017), Marandino (2017) e Selles (2018), com base nos quatro pilares apresentados neste artigo que nos permitem teorizar o Trabalho Pedagógico dos Professores de Biologia, é possível apresentar duas formas de enfrentamentos, lutas e resistências, a saber:

1. as que se dão nos movimentos sociais e populares por condições dignas de trabalho, salários, carreira, lutas pela educação pública; e

2. as que se dão contra os ataques à Prática Pedagógica, à Prática Docente, à especificidade da ação docente no Trabalho dos Professores de Biologia; ou seja, as políticas que tentam controlar os conteúdos a serem ensinados, a liberdade de ensinar, a pluralidade de ideias e de conhecimentos.

Ambas as resistências, lutas e enfrentamentos acontecem na cotidianidade da vida, nos movimentos sociais, sindicatos, manifestações populares, até a compreensão da própria Prática Pedagógica como resistência aos ataques à classe trabalhadora, aos docentes e às condições precárias de trabalho. Por exemplo, as resistências às ações políticas ultra-neo-conversadoras, as quais emergem atualmente no cenário brasileiro por meio de projetos como Escola sem Partido, o ataque à educação por ocasião de certa 'ideologia de gênero' que é inexistente, entre outros ataques que também incidem diretamente nos conteúdos que compõem as Ciências Biológicas. 
Políticas essas que visam e implicam o controle político e ideológico dos docentes e suas práticas pedagógicas, especificamente nas Instituições Escolares Públicas.

O projeto de Lei do Senado (PLS) no 193/2016, de autoria do Senador Magno Malta, que pretende incluir na Lei de Diretrizes e Bases da Educação Nacional Brasileira (BRASIL, 1996) e o Programa Escola sem Partido, bem como, as iniciativas sobre homeschooling, e os discursos sobre a 'ideologia de gênero' (a qual não existe), compõem o cenário geral das iniciativas políticas de precarização e desvalorização dos trabalhadores da Educação e o controle político-ideológico da docência pelo movimento neoconservador contemporâneo.

Nesse cenário político e educacional, por exemplo, como abordar os conteúdos relacionados à Sexualidade Humana/Anatomia e à Fisiologia dos Sistemas Reprodutor em face dos ataques do Escola sem Partido e/ou Ideologia de Gênero, sem abordar aspectos relacionados aos Estudos de Gênero, à Diversidade Sexual, à Afetividade e à Sexualidade, Identidade de Gênero, entre tantos outros aspectos que estão permeados e compõem os conteúdos da área de Ciências Biológicas?

Outro exemplo, como abordar os conteúdos relacionados à Evolução e Origem da Vida em tempos de pós-verdade, de fakenews, de terraplanistas (pessoas/grupos que acreditam que a Terra é plana), frente às pautas do Escola sem Partido que são alicerçadas na religião e não nos conhecimentos científicos historicamente produzidos e sistematizados pela humanidade?

Esses exemplos pontuais - e tantos outros que poderiam ser trazidos - fortalecem a necessidade da compreensão do Trabalho dos Professores de Biologia, para uma emancipação política e humana pautada na criticidade, numa perspectiva histórica e social da educação, nos conhecimentos científicos que fundamentam as Ciências da Educação e as Ciências Biológicas.

\section{Considerações finais}

Retoma-se aqui a problemática que balizou este ensaio teórico-conceitual: qual é o trabalho dos professores na Biologia? A teorização que buscou responder à questão foi construída nos relatos das pesquisadoras e pesquisador da área de Educação e Ensino de Ciências e Biologia.

Teorizou-se, a partir das entrevistas, que o Trabalho Pedagógico dos Professores de Biologia é constituído por quatro pilares fundamentais, sendo:

1. as Concepções Filosóficas sobre a Educação e o Ensino de Biologia;

2. o Trabalho Pedagógico dos Professores de Biologia;

3. as Condições de Trabalho dos Professores de Biologia e oTrabalho Pedagógico dos Professores de Biologia; e

4. os Enfrentamentos, Lutas e Resistências dos Professores de Biologia.

Frente à compreensão do Trabalho Pedagógico dos Professores de Biologia nos quatro pilares que o fundamentam, com as contribuições dos pesquisadores, ressaltase que, mesmo diante dos desafios e das lutas necessárias por uma Educação em Ciências e Biologia para a emancipação política e humana, para a criticidade, faz-se necessário não perder a esperança de, por meio dos processos educativos, propor uma transformação social da realidade. 
A teorização apresentada não encerra o debate sobre o Trabalho dos Professores de Biologia, pela densidade teórica que o abarca e pelo limite de páginas de um ensaio para um periódico. Mas, este ensaio aponta elementos que oxigenam a área de pesquisa e sugere a importância e a necessidade de pesquisas que ampliem e aprofundem essas perspectivas teóricas e analíticas para a abordagem do Trabalho dos Professores de Biologia no âmbito filosófico, pedagógico e político.

Em síntese, considera-se o Trabalho Pedagógico dos Professores de Biologia uma práxis social que o é em si. Essa compreensão abre a possibilidade de olhar criticamente para os cenários de ataques à Educação, de modo a compreender o Trabalho dos Professores de Biologia e a centralidade dos conhecimentos das Ciências Biológicas como meios para a resistência diante da negação do conhecimento e dos professores e professoras enquanto 'personificação' deste; e a precarização e a desvalorização dos professores que, de certo modo, também são resultado do processo da negação do conhecimento e acentuadas por esse processo.

Por fim, as palavras da pesquisadora Selles sintetizam os desejos e os anseios de transformação, de lutas e resistências no Trabalho dos Professores de Biologia, em suas dimensões filosóficas, pedagógicas e políticas:

\begin{abstract}
Então eu acredito que temos muitos sonhos para profissão docente, muitos sonhos para docência, muitos sonhos para os processos de ensino, encontramos dificuldades de concretizá-los porque, muitas vezes, há dilemas que são colocados diariamente. Eu considero que a gente está vivendo um momento desses no Brasil e eu penso que o professor vai se cansando de não ser ouvido, ele vai se cansando de estar sempre sendo um sujeito de segunda classe. E eu acredito que o esforço maior que a gente como formador e como professor se reconheça, não aceite esse lugar de subalternidade, descaso e consiga enfrentar os inúmeros desafios colocados pelos nossos alunos, pelas comunidades com as quais temos que conviver, com as próprias relações viciadas dentro da escola. Mas, enfim, enfrentar isso tudo ainda com esperança, sem deixar que o sonho envelheça nesse processo todo. (SELLES, 2018, informação verbal).
\end{abstract}

\title{
Agradecimentos
}

O autor agradece às pesquisadoras e ao pesquisador que gentilmente contribuíram com esta pesquisa e teorização e à Coordenação de Aperfeiçoamento de Pessoal de Nível Superior (CAPES), código de financiamento 001, pelo auxílio financeiro que possibilitou permanecer no programa de pós-graduação (doutorado).

\section{Referências}

ALONSO, M. O trabalho coletivo na escola. In: FORMAÇÃO de gestores escolares para a utilização de tecnologias de informação e comunicação. São Paulo: Pontifícia Universidade Católica de São Paulo, 2002. p. 23-28. Disponível em: https://cutt.ly/UWL8Afg. Acesso em: 28 dez. 2020.

AYRES, A. C. B. M. As tensões entre a licenciatura e o bacharelado: formação dos professores de biologia como território contestado. In: MARANDINO, M.; SELLES, S. E.; FERREIRA, M. S.; AMORIM, A. C. R. (org.). Ensino de biologia: conhecimentos e valores em disputa. Niterói: EdUFF, 2005. p. 182-197.

BRASIL. Lei no 9.394, de 20 de dezembro de 1996. Estabelece as diretrizes e bases da educação nacional. Brasília: Presidência da República, 1996. Disponível em: https://cutt.ly/RWZws2l. Acesso em: 28 dez. 2020.

BRASIL. Ministério da Educação. Base nacional comum curricular: educação é a base. Brasília: MEC, 2018. Disponível em: https://cutt.ly/ZWZwjm3. Acesso em: 28 dez. 2020. 
BRASIL. Ministério da Educação. Conselho Nacional de Educação. Parecer CNE/CES n 1.301/2001. Diretrizes curriculares nacionais para os cursos de ciências biológicas. Brasília: MEC, 2001. Disponível em: https://cutt.ly/1WZwvlU. Acesso em: 28 dez. 2020.

BRASIL. Ministério da Educação. Conselho Nacional de Educação. Parecer CNE/CP No 2/2015, [de 9 de junho de 2015]. Diretrizes curriculares nacionais para a formação inicial e continuada dos profissionais do magistério da educação básica. Brasília: MEC, 2015a. Disponível em: https://cutt. ly/NWZwQlu. Acesso em: 28 dez. 2020.

BRASIL. Ministério da Educação. Conselho Nacional de Educação. Resolução CNE/CP 1, de 18 de fevereiro de 2002. Institui diretrizes curriculares nacionais para a formação de professores da educação básica, em nível superior, curso de licenciatura, de graduação plena. Brasília: MEC, 2002a. Disponível em: https://cutt.ly/XWZwStx. Acesso em: 28 dez. 2020.

BRASIL. Ministério da Educação. Conselho Nacional de Educação. Resolução no 1, de 27 de outubro de 2020. Dispõe sobre as diretrizes curriculares nacionais para a formação continuada de professores da educação básica e institui a base nacional comum para a formação continuada de professores da educação básica (BNC-formação continuada). Disponível em: https://cutt.ly/ FWZwKQQ. Acesso em: 16 jun. 2021.

BRASIL. Ministério da Educação. Conselho Nacional de Educação. Resolução CNE/CP 2, de 19 de fevereiro de 2002. Institui a duração e a carga horária dos cursos de licenciatura, de graduação plena, de formação de professores da educação básica em nível superior. Brasília; MEC, 2002b. Disponível em: https://cutt.ly/jWZeJmW. Acesso em: 28 dez. 2020.

BRASIL. Ministério da Educação. Conselho Nacional de Educação. Resolução $n^{\circ} 2$ de $1^{\circ}$ de julho de 2015. Define as diretrizes curriculares nacionais para a formação inicial em nível superior (cursos de licenciatura, cursos de formação pedagógica para graduados e cursos de segunda licenciatura) e para a formação continuada. Brasília: MEC, 2015b. Disponível em: https://cutt. ly/8WZeaJ2. Acesso em: 28 dez. 2020.

BRASIL. Ministério da Educação. Conselho Nacional de Educação. Resolução no 2, de 20 de dezembro de 2019. Define as diretrizes curriculares nacionais para a formação inicial de professores para a educação básica e institui a base nacional comum para a formação inicial de professores da educação básica (BNC-formação). Disponível em: https://cutt.ly/2WZwUq6. Acesso em: 16 jun. 2021.

CANDAU, V. M. Formação continuada de professores: tendências atuais. In: CANDAU, V. M. Magistério: construção cotidiana. Rio de Janeiro: Vozes, 2003. p. 51-68.

MARCELO GARCÍA, C. Formação de professores: para uma mudança educativa. Porto: Porto Ed., 1999.

MORAES, M. C. M. Indagações sobre o conhecimento no campo da educação. Perspectiva, Florianópolis, v. 27, n. 2, p. 315-346, 2009a. DOI: https://doi.org/gvnb.

MORAES, M. C. M. "A teoria tem consequências": indagações sobre o conhecimento no campo da educação. Educação \& Sociedade, Campinas, v. 30, n. 107, p. 585-607, 2009b. DOI: https://doi.org/ d38db2.

PIMENTA, S. G.; LIMA, M. S. L. Estágio e docência. São Paulo: Cortez, 2004.

SOUZA, R. D. Trabalho e formação de professores de biologia no estado do Paraná, Brasil. 2019. Tese (Doutorado em Educação Científica e Tecnológica) - Universidade Federal de Santa Catarina, Florianópolis, 2019. Disponível em: https://repositorio.ufsc.br/handle/123456789/215177. Acesso em: 16 jun. 2021. 